$\xi=$ 줄

\title{
High grade myoepithelial carcinoma of the maxillary sinus
}

\author{
Bharati Patil, Sushmini Hegde, Karthik D Yadav* \\ The Oxford Dental College, 10th Milestone, Bommanahalli, Hosur Road, Bangalore- 560 102, India \\ *Corresponding author E-mail: karthikyadavd@gmail.com
}

\begin{abstract}
Myoepithelial carcinoma is a rare tumor of salivary glands, the most frequent site being the parotid gland. Myoepithelial carcinoma of the maxillary sinus has only been reported very few times. As the lesion is very rare in the maxillary sinus and due to the lack of specific guidelines for its treatment, its prognosis remains to be poor. We report a rare case of myoepithelial carcinoma in the maxillary sinus and discuss its diagnostic and therapeutic aspects.
\end{abstract}

Keywords: Myoepithelial Carcinoma (MC); Myoepithelioma; Salivary Glands; Calponin; Tumors

\section{Introduction}

Myoepitheliomas are benigntumors of the salivary glands which make up about $1 \%$ of the salivary gland tumors with a malignant transformation rate of $0.1 \%$ (Colella G, Das et al,Magliulo Get al.Although many other sites of origin such as lungs, trachea, oral cavity, larynx and breast have been reported. Parotid gland still remains the most frequent site of MC (Soon G\&Petersson F, Burket LW 2015, Ch 8: p221). To the best of our knowledge there are very few reports affecting the maxillary sinus in the literature, which makes the maxillary sinus an unusual location and is considered difficult to access for the head and neck surgeon due to the presence of vital structures in the region. As the tumor is so rare, there are no such specific indications and guidelines for its management. Here we present a case of myoepithelial carcinoma of the maxillary sinus and discuss its diagnostic aspects and review of literature.

\section{Case report}

A 55-year-old male reported to the department of oral medicine and radiology with the chief complaint of pain in the upper right posterior region since a month after extraction and pain has in creased since then and does not relieve on medication. No significant medical history was elicited. Patient gives a habit history of smoking 24-36 biddis/day since 25 years.

On examination a well defined swelling measuring about $2 \times 3 \mathrm{~cm}$, from infraorbital margin with a line drawn from the tragus of the ear to the corner of mouth and from corner of the mouth to the tragus was present. Intraorally an ill-defined solitary, sessile, mixed red-white exophytic growth with irregular surface extending from the distal aspect of 16 into the soft palate. On palpation, it was tender and firm in consistency. Right 2 submandibular lymph nodes were firm, fixed and tender. A Provisional diagnosis of Malignancyirt upper right alveolus and palate were given.

Complete Blood Count and Random Blood Sugar were within a normal range. Computed tomography (CT) scans depicted a large destructive soft-tissue mass involving the right maxilla centered in the region of the maxillary sinus and destructing the right alveolus and extending into the right intra orbital region with infiltration of right masticatory space and the pterygopalatine fossa. Biopsy showed non keratinized stratified squamous epithelium with underlying connective tissue, which consists of nests of tumor cells varying from epithelioid to spindle to clear cells. Cellular pleomorphism and abundant mitotic figures were also seen with muscle invasion. Tumor cells were positive for calponin. A diagnosis of high-grade myoepithelial carcinoma was rendered.

A final diagnosis of myoepithelial carcinoma of the maxillary sinus was rendered. The prognosis was poor. The patient underwent excision of the tumor along with dissection of level $(1-4)$ lymph nodes on the ipsilateral side. The patient was referred to oncology center, where he underwent radiotherapy along with chemotherapy. The patient recuperate dwell. However, due to multi organ metastasis the patient was lost within 6 months.

\section{Discussion}

Approximately $1 \%$ of primary tumors in salivary glands are myoepitheliomas, in which $70 \%$ arise in the parotid gland, $20 \%$ in submandibular gland and $10 \%$ in the minor salivary glands (Burket LW 2015, p221, Hata M et al). In our review of the literature, we discovered only seventeen previously published cases of malignant myoepithelioma. Malignant myoepithelioma in the maxillary sinus is extremely rare. To the best of our knowledge, we report the fourth case of a patient with malignant myoepithelioma in the maxillary sinus.

MC are epithelial tumors, which can occur as an adjuvant to preexisting benign lesions like pleomorphic adenomas or benign myoepitheliomas. They are usually painless and insidious in onset, affecting individuals over 50 years of age (mean $->60$ ) with no definite sex predilection and the parotid gland being the most commonly affected site which was also seen in our case. The other sites being maxillary sinus, larynx, gums, retromolar area and breast(Burket LW 2015, p221, Hata M et al, Thayumanavan B \& Vani NV, Dhawanet al, Shafer 2009 p239-240).It It is a rapidly growing tumor with extensive local growth, invasion of surrounding tissues and infrequent cervical node metastasis, but high rates of distant metastasis have been reported. When they occur in the 
maxillary sinus, the symptoms are nasal obstruction, ear fullness, serous otitis media, and conductive hearing loss (Dhawanet al).

The criteria that point out the malignant form of myoepithelioma include their cellular pleomorphism, necrosis, destructive infiltrating growth, and an increased mitotic activity. Locally, this type of tumor is particularly destructive, but its clinical and biological features are not yet fully understood (Hata $\mathrm{M}$ et al). Histologically, myoepithelioma cells can be classically divided into 4 subtypes of epithelioid cells, spindle-shaped cells, plasmacytoid (hyaline) cells and clear cells which the present tumor showed, based on morphology(Hata aM M et al, Thayumanavan B \& Vani NV).

Due to its painless nature and insidious onset, diagnosis can be delayed by months or even years. Biopsy remains the gold standard for the confirmatory diagnosis. Diagnostic imaging (CT and MRI) helps to determine the site and the extension of the tumor which helps in surgery (Dhawanet al). Due to their extensive involvement, MCs in the parotid may require neck dissection procedures involving the lymph nodes due to metastasis. Hence, they serve both as a diagnostic as well as a therapeutic procedure.

The treatment of choice for MCs is surgical excision. The primary surgical management still remains the mainstay of success and is a major factor of the outcome of the treatment, followed by radiotherapy and chemotherapy, which is mostly determined by the extent of the tumor. However, the controversy regarding the use of treatment modalities still persists (Burket LW 2015, Ch 8: p221).

\section{Conclusion}

Myoepitheliomas are relatively rare tumors of the salivary glands, with a malignancy potential. As it is a silent neoplasm, they are neither easy to diagnose nor are there any specific protocol/guidelines for its treatment, which makes the prognosis poor (Burket LW 2015, p221).

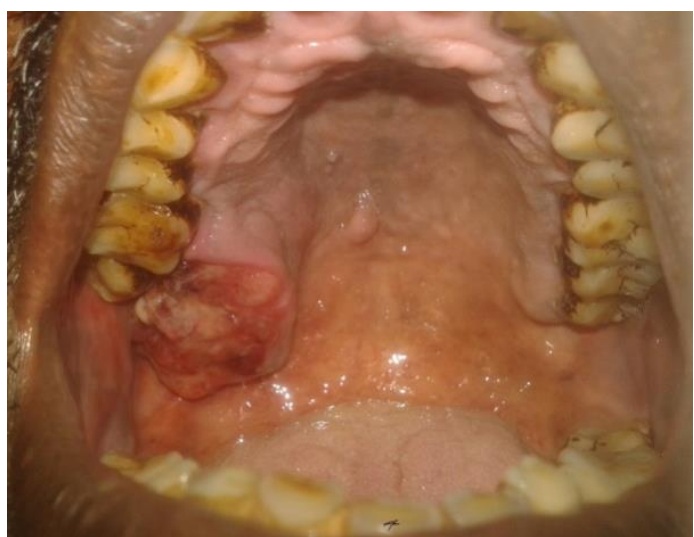

Fig. 1: Lesion Involving the Right Alveolar Process and the Palate.

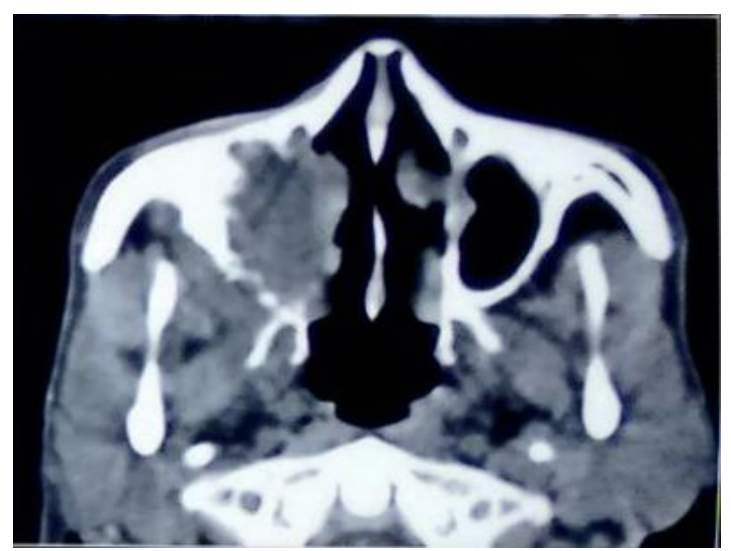

Fig. 2: Infiltration of Right Maxillary Sinus.

\section{References}

[1] Colella G, et al. Epithelial-myoepithelial carcinomaof the parotid gland. Oral Oncology extra (2004) $40 \quad 29-32$. https://doi.org/10.1016/j.ooe.2003.12.003.

[2] Das C,Singh MK, Majumder A, Das S, Hazra TK. Myoepithelial Carcinoma in maxilla: A rare case report. ClinRhinolInt J 2012; 5 (1):35-37. https://doi.org/10.5005/jp-journals-10013-1115.

[3] Magliulo G, Pulice G, Fusconi M and Cuiuli G: Malignant myoepithelioma of the rhinopharynx: case report. Skull Base 15: 113-117, 2005. https://doi.org/10.1055/s-2005-870596.

[4] Soon G,Petersson F. Myoepithelial Carcinoma of the Nasopharynx: Report of a Rare Case and a Review of the Literature. Head and Neck Pathol (2015) 9:474-480. https://doi.org/10.1007/s12105015-0638-9.

[5] Burket LW, Greenberg MS, Glick M, Ship JA. Burkets Oral Medicine. 11th ed: BC Decker Inc; 2015, Ch 8: p221.

[6] Hata $\mathrm{M}$ et al. Malignant Myoepithelioma in the Maxillary Sinus:Case Report and Review of the Literature. Anticancer reaearch. 29: 497-502 (2009).

[7] Dhawan A, Shenoy A, Sriprakash D. Myoepithelial carcinoma of the nasopharynx: Case report of a rare entity. Natl J Maxillofac Surg. 2011 Jul-Dec; 2(2): 207-209. https://doi.org/10.4103/09755950.94484.

[8] Thayumanavan B, Vani NV. Myoepithelial carcinoma of palate; Case report. Indian J PatholMicrobiol: 57:85-8.

[9] Shafer, Hine, Levy. Text book of oral pathology. 6th Ed; Elsevier, New Delhi;2009: p224,239-240. 